Portland State University

PDXScholar

12-8-1977

\title{
Analysis of the Two Word Stage of Language Development: An Ideographic Study
}

Lou Ann McCoy

Portland State University

Follow this and additional works at: https://pdxscholar.library.pdx.edu/open_access_etds

Part of the Speech Pathology and Audiology Commons Let us know how access to this document benefits you.

Recommended Citation

McCoy, Lou Ann, "Analysis of the Two Word Stage of Language Development: An Ideographic Study" (1977). Dissertations and Theses. Paper 1332.

https://doi.org/10.15760/etd.1331

This Thesis is brought to you for free and open access. It has been accepted for inclusion in Dissertations and Theses by an authorized administrator of PDXScholar. Please contact us if we can make this document more accessible: pdxscholar@pdx.edu. 
ANALYSIS OF THE TWO WORD STAGE OF LANGUAGE

DEVELOPMENT: AN IDEOGRAPHIC STUDY

by

LOU ANN McCOY

A clinical project submitted in partial fulfillment

of the requirements for the degree of

MASTER OF SCIENCE IN SPEECH COMMUNICATION:

with an emphasis in

SPEECH PATHOLOGY/AUDIOLOGY

Portland State University

1977 
TO THE OFFICE OF GRADUATE STUDIES AND RESEARCH:

The members of the Committee approve the clinical research project of Lou Ann McCoy presented December 8, 1977.

Mary E. Gordon, Chairperson

Robert L. Castee1

Georgie Hustead

Ronald Smith 
ACKNOWLEDGMENTS

Many people have been involved, both directly and indirectly, in this clinical project. First, I thank my committee chairperson and graduate advisor, Mrs. Mary E. Gordon, for her support and patience with me during my program at Portland State University. To Dr. Robert L. Casteel I give thanks for his show of confidence in my ability to tackle this project and for his consistent reinforcement of my interest in the area of language development. I thank Georgie Hustead and Dr. Ronald Smith for their time and suggestions with the project.

I greatly appreciate Mr. and Mrs. Richard Werschkul, the parents of the child in this study, for making it possible to observe Leslie in their home. This was an experience I'11 always remember. And, of course, a special thanks to Leslie for being the right age at the right time. She allowed me to observe and interact with her and become my special little friend.

Finally, I wish to say thank you to my family. They have been my rea1 support, both through undergraduate school in Illinois and graduate school in Oregon. Somehow they were always there when I needed a shoulder to cry on, a hug of reassurance, or a smile of pride. Thanks! I love you! 
TABLE OF CONTENTS

PAGE

ACKNOWLEDGMENTS . . . . . . . . . . . . . . . . . . . . . iii

LIST OF TABLES . . . . . . . . . . . . . . . . . . . . vi vi

LIST OF FIGURES . . . . . . . . . . . . . . . . . . . . vii

CHAPTER

I INTRODUCTION . . . . . . . . . . . . . . . . 1

Statement of Purpose ........... . 3

Definitions .............. . . . 3

II REVIEW OF THE LITERATURE . . . . . . . . . . . . 7

Syntactically Based Underlying Structures . . . 8

Pivot-Open Combinations

Rich Interpretation

Semantically Based Underlying Structures .... 10

Input Markers

Case Grammar

Integrating Semantic Relations

Developmental Sentence Analysis ....... 15

III RESEARCH PROJECT DESIGN . . . . . . . . . . 19

Subject . . . . . . . . . . . . . 19

Procedures . . . . . . . . . . . . 19

Evaluation Instruments . . . . . . . . 20

Language Sample Analysis . . . . . . . . 24 
IV

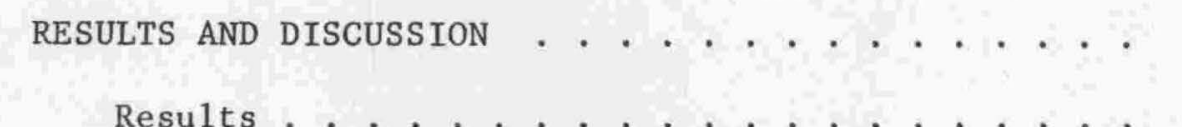

Results

Grammatico-Semantic Analysis

Developmental Sentence Analysis

Mean Length of Utterance

Discussion ................. 41

V SUMMARY AND IMPLICATIONS . . . . . . . . . . . . . . . 49

Summary .. . . . . . . . . . . . . . 49

Implications . . . . . . . . . . . . 50

Clinical

Research

SELECTED BIBLIOGRAPHY ...................... 53

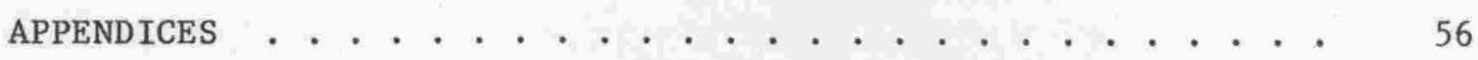

A OBSERVER'S NOTES ...................... 56

B DEVELOPMENTAL SENTENCE TYPES (DST)

CLASSIFICATION OF PRESENTENCES . . . . . . 57

C DEVELOPMENTAL SENTENCE SCORING (DSS) . . . . . . 59

D DEVELOPMENTAL SENTENCE TYPES SHOWING LOCATION OF BROWN'S SEMANTIC RELATIONSHIPS ....... . 61 


\section{LIST OF TABLES}

TABLE

PAGE

I SCHEDULE OF CHILD'S OBSERVATION SESSIONS . . . . . .

II PERCENTAGE OF GRAMMATICO-SEMANTIC RELATIONSHIPS

FOR EACH SESSION . . . . . . . . . . . . . .

iI I PERCENTAGE OF DEVELOPMENTAL SENTENCE TYPES . . . . . . 34

IV BREAKDOWN OF DEVELOPMENTAL SENTENCE TYPES . . . . . 36

V BREAKDOWN OF DEVELOPMENTAL SENTENCE SCORING . . . . . 39 


\section{LIST OF FIGURES}

\section{F IGURE}

PAGE

1 Brown's (1970) semantic classification of two-word utterances . . . . . . . . . . .

2 Summary of links between sensory-motor cognition and language (Edwards, 1973). . . . . . . . 


\section{CHAPTER I}

\section{INTRODUCTION}

Chomskyan transformational grammar emerged in 1957 as a model of analysis for language acquisition and development. Accompanying the theory were the implications of underlying structural relations that have syntactic characterization, e.g., subject and predicate, word order, articles and plural and tense markers (Clark, 1974). Subsequently research in language development was so heavily influenced by Chomsky's theory that numerous studies dealt with the acquisition of syntax in explaining child language acquisition; the cognitive phenomena that may underlie language tended to be overlooked.

McNeil1 (1971), a spokesman for transformational grammar, hypothesized that the beginning of language acquisition is developed on the "concept of a sentence." The concept of a sentence, as a method for organizing linguistic information, "can appear early because it reflects specific linguistic predispositions, some of which may be innate."

Another theory proposed by generative semanticists (Fillmore, 1968; and McCawley, 1968) states semantic concepts are the primitive structural components of sentences. Concepts are not specifically linguistic knowledge, but determined more by a general innate cognitive capacity (Schlesinger, 1971b). While McNeill and others have supported the theory that the input to child language acquisition is the linguis- 
tic productions of adults, Schlesinger pointed out these linguistic productions are paired with the situation about which the adult talks and which is perceived by the child learning language in terms of semantic categories. Schlesinger (1971b) and Kuczaj (1975) further stated the attainment of semantic categories or relationships is dependent on the child's general cognitive development and not on innate syntactical concepts.

The beginning of language acquisition presents itself with the child not composing word assemblies according to grammatical rules such as noun phrase, verb phrase and prepositional phrase, but more so with the child expressing the semantic relations he encounters in his interaction with the environment. The child may show recognition of the semantic relationships first on a non-verbal level before they are marked on a grammatical level in expressive speech. The child's meanings may be inferred from the intonation patterns, gestures, actions and contextual cues and, finally, from the words he uses. Meaning may be derived in the semantic features of the words he combines and gradually the child will use morphological inflections (e.g., plural and tense markers) and function words to mark these semantic relationships (Brown, 1973).

The importance of understanding semantics and semantic relationships when viewing child language has encouraged development of criteria for analysis of semantic relationships in the two-word stage of language development (Brown, 1973) and even more recently in the oneword stage (Brown, 1973; and Greenfield and Smith, 1976). Large samples of spontaneous language, both through formal observations and 
parent diaries (Greenfield and Smith, 1976), and computations of Mean Length of Utterance (MLU) (Brown, 1973) have been the bases of many of the studies concerned with semantic analysis.

\section{STATEMENT OF PURPOSE}

The purpose of this longitudinal, ideographic clinical research project was to analyze a corpus of expressive language emitted by a child at the two-word stage of language development via grammaticosemantic relationships (Brown, 1973) and via Developmental Sentence Analysis (Lee, 1974).

The specific questions posed were:

1. Does the child express grammatico-semantic relations in a particular developmental order?

2. Do new grammatico-semantic relationships emerge as Mean Length of Utterance increases in the language sample?

3. What are the demonstrated differences between using both the grammatico-semantic relationships and Developmental Sentence Analysis?

4. Does one system of analysis provide more information at one point in language development than the other?

\section{DEF INITIONS}

The following definitions are provided in order to clarify the terminology used in this review of the literature.

Brown's Stages. Brown (1973) has described five stages of development. The two stages most relevant to this study are:

Stage I (MLU) ---1.99. Relations or Roles within the Simple Sentence. It is characterized by the semantic roles and grammatical relations used by the child in expressive language. 
Stage II (MLU) 2.-2.75. Modulations of Meaning within the Simple Sentence. It is characterized by the emergence of grammatical morphemes and changes of meaning or expansions of meaning the child uses.

Case Grammar. A modification to transformational grammar comprised of a set of universal, presumably innate, concepts which identify certain types of judgments human beings are capable of making about the events going on around them, judgments about who did it, to whom it happened and what was changed (Fillmore, 1968).

Cases. Edwards (1973) has defined the following terms in reference to Fillmore's cases:

Agent is typically animate and perceived as the instigator of an action identified by the verb (e.g., as "John" in "John opened the door").

Instrument is the inanimate force or the object causally involved in the action or state identified by the verb (e.g., as "key" in "The key opened the door").

Object is semantically the most neutral case, the case of anything which is representable by a noun whose role in the action or state identified by the verb is identified by semantic interpretation of the verb itself; therefore, the concept should be limited to things which are affected by the action or state identified by the verb. This should not be confused with the notion of direct object. The role of the object is 1) a particular state or condition, 2) undergoing a change of state or position or 3) affected by an agent and/or instrument.

Experiencer is the animate being who is said to be having a mental experience (e.g., a perception in "John heard a noise"; a cognition in "John knew the answer"; and a reaction in "John liked the play").

Phenomenon is the fact or item which is perceived, known or related to by the experiencer (Ha1liday, 1967) (e.g., "book" in "John saw the book").

Location is the spatial position or orientation of the object (Chafe, 1970) (e.g., "table" in "The book is on the table").

Source and Goal cases are where a locative verb specifies movement of the object towards, into, out of, away from, etc., the named position; that position is termed source or goal as appropriate (Edwards, 1973). Fillmore (1971) defines source as a "place from which the object moves (e.g., "the table" in "The book fell off the table") and 
goal as the place to which the object moves (e.g., "the table" in "Henry threw the book onto the table").

Possessor is typically the human possessor of the object where the possessive relation is static (e.g., "John" in "It is John's book").

Beneficiary is used when the verb specifies that the object has changed possession (e.g., "John gave Henry (beneficiary) a bicycle").

Result is the entity that comes into existence as a result of the action (e.g., "house" in "They built a house").

Cognition. The process of knowing in the broadest sense, including perception, memory and judgment.

Complete Sentence. The basic sentence containing the elements of subject and verb (Lee, 1974).

Deep Structure. Base or underlying relationships between the morphemes and a sentence with information for both syntactic and semantic interpretation.

Innate. A term used in linguistic theory stating that "human beings are endowed with a biological capacity for language" (Dale, 1972).

Input Marker. A term used for the formalized representation of intentions specifying semantic notions in the deep structure, but they do not contain any information about syntactic categories or word order (Schlesinger, 1971a).

Lexicon. A set of words of a language; vocabulary.

Linguistic Knowledge. The speaker's internalization of a rule system, or his/her structural knowledge of the language he/she speaks. Linguistic knowledge would contain elements of syntax, morphology, phonology and semantics and also how these are expressed in surface structure.

Mean Length of Utterance (MLU). A simple index used to measure grammatical development. In early stages of language development, it is sensitive to the increase in linguistic knowledge. MLU is calculated using 100 utterances in the transcription of a language sample, and dividing the number of morphemes by 100 (Brown, 1973).

Object Permanence. A concept expressed by Piaget that describes the cognitive development a child shows in his actions on the environment. The concept is defined as the idea that an object does not cease to exist when it is no longer within the visual field (Edwards, 1973). 
Phrase Structure Grammar. A theory of grammar that indicates which strings or words are sentences.

Semantics. Part of the underlying or deep structure of language development that is possibly part of the more general cognitive structure, containing meanings relating to experiences a human being has about the world around him.

Surface Structure. The actual utterances heard; the phonetically represented utterance paired with semantic interpretations and syntactic order (Slobin, 1973).

Transformational Grammar. A theory of language developed by Chomsky to describe language. There are two levels: deep structure and surface structure that are related by rules of transformation (e.g., passive, negative, interrogative) (Dale, 1972). 


\section{CHAPTER II}

\section{REVIEW OF THE LITERATURE}

The concern of this investigator has been the semantic relationships between words at the two-word stage of language development. It has been postulated that the child learning language masters concepts pertaining to these relations (e.g., agent, action, object concepts). The question raised in recent research has been focused on whether these relational concepts are specifically linguistic in nature or a part of the general cognitive categories of children learning language (Bowerman, 1973, 1974; Clark, 1974; and Schlesinger, 1974).

Bloom (1970) has suggested that learning to distinguish, to understand and to express semantic relations not only precedes acquisition of a syntactic or linguistic code but also directs later usage of the code. The subsequent development of syntax is looked upon as a device the child acquires to transmit his set of semantic relations in complex and unique ways (Chafe, 1970; and Bowerman, 1973).

Bloom differs in her approach to explaining the early stages of language development from the psycholinguists such as Chomsky and McNei11. Early language acquisition and development for these theorists were created using a syntactic or linguistic based model implementing the grammatical models of subject, predicate and object of the verb. 


\section{SYNTACTICALLY BASED UNDERLYING STRUCTURES}

The assumption that the relational concepts are linguistic in nature follows the Chomskyan transformational grammar model. McNeill (1971) has hypothesized that the "concept of a sentence" is part of the very beginning of language development. The "concept" is used as a method of organizing linguistic information into unified structures. He explains that words fit into grammatical categories and these grammatical categories are related to specific grammatical functions expressing subject, predicate and object of the verb. McNeil1 (1971) further proposed that knowledge of these grammatical categories is "innate and guides understanding and production from the very beginning of language development."

\section{Pivot-0pen Combinations}

In the early sixties, two-word combinations were described syntactically as using the pivot-open system. The pivot class was described as small in the quantity of words, showing slow expansion and containing words used frequently in the child's speech. Words such as "allgone," "more," "on" and "off" might be pivot words. The term pivot was implemented because the child appears to be attaching other words to these pivot words. In contrast, the open class is large in numbers of words. It shows rapid expansion and contains words not found in the pivot class. Words such as "shoe," "truck," "milk" and "sock" may be open class words.

New evidence in child language development has led some investigators (Bloom, 1970) to state that pivot-open grammar is inadequate 
but warrants discussion. A pivot word may be in the first or second position, but accordingly each pivot has its own fixed position. Open class words can combine with either the first or second position pivot word or with another open class word.

The inadequacies of the theory of pivot-open grammar are:

1) Some children's speech cannot be described accurately and 2) failure to capture the richness of the linguistic system (Bowerman, 1973). Bloom $(1970,1971)$ and Lee (1974) stated the use of pivot-open constructions as an analysis for child language did not account for all the rules a child demonstrates in language. Pivot-open grammar is too simple and restrictive in that it says little about the relations between words in a sentence. It was due to these restrictions that changes in language development theory arose.

\section{$\underline{\text { Rich Interpretation }}$}

Bloom (1970) used the concept of "rich interpretation" in describing children's utterances. Rich interpretation was conceived as being the combination of structural characteristics of the utterance and the non-1inguistic information surrounding the utterance. Transformational grammar was the model for rich interpretation in that the structural characteristics were generated by phrase structure rules specifying hierarchical organization of the elements of a sentence and ordering these elements (e.g., S NP + VP). Semantic interpretation was presumed to be derived from the rules operating on the syntactically based underlying structure. The idea of rich interpretation appeared to say that the meaning expressed in an utterance was secondary to a syntactic or word order based deep structure. 
SEMANTICALLY BASED UNDERLYING STRUCTURES

Others in the field of psycholinguistics and child language development have tended to disagree with the notion that a child is knowledgeable of the rather large categories of subject, predicate and object of the verb (Fillmore, 1968; McCawley, 1968; Brown, 1970;

Slobin, 1970; and Schlesinger, 1971, 1974). Schlesinger (1974) viewed structural relationships of child language as semantic in nature. The semantic concepts of agent, action and object are not attained due to any innate syntactic knowledge, but are determined by a more general innate cognitive ability.

Bowerman (1974) examined the two fields of thought, semantic versus syntactic, underlying structures and reported the syntactic concept of "subject of" in the deep structure does not relate with just one semantic concept. "Subject of" can be an experiencer, an agent or an instrument. Using the subject category, therefore, becomes an economical device for using one rule to express three difference semantic relations. Bowerman (1974) concluded that children learning language operate initially with semantic concepts which the child verbalizes. The child then learns that nouns expressing the semantic relations of experiencer, agent and instrument follow similar rules of position in a sentence. The "subject" concept is abstracted from these observations and the child's system of rules in his native language is developed. This pattern may be followed for some of the other syntactic categories such as predicate and direct object. 


\section{Input Markers}

The term input marker or I-marker represents semantic intentions and serves as input to the sentence production mechanism. For example, agent-action and action-object relations are I-markers. Each child learns the I-markers for his particular language along with syntactical constructions and not as an independent system. According to Schlesinger (1974), I-markers are part of the child's cognitive structure. There are as many relations (e.g., agent-action) as are necessary to account for the syntactical rules which map the surface structure. As long as there is a difference made linguistically, there is a semantic relation put into an I-marker.

\section{Case Grammar}

The case grammar of Fillmore (1968) was implemented by Bloom (1970) and Brown (1970, 1973) in explaining a child's early language for a more accurate and "richer interpretation." By using the case grammar approach, sharper distinctions have been made between semantic and grammatical or syntactic relations. Semantic relations are the concepts a child sees and experiences in his/her daily interactions with the environment. Grammatical relations are the syntactic rules for formulating sentences about those perceptions and experiences (Lee, 1974). The child utilizes the cognitive skills and the linguistic knowledge he/she holds to interpret the information seen and experienced (Kuczaj, 1975).

According to Brown (1973), the child's earliest word combinations are not grammatical relations (i.e., actor-action-object), but are the semantic relations of agent, action, location, attribute, et cetera, 
which the child is experiencing in activities and observations. These semantic relations are then coded into grammatical form as dictated by the language the child hears as he/she matures in language development. Children then do not begin to speak in the subject-verb-object form; however, it is speculated to be the "first adaptation they make to conform with adult language" (Lee, 1974).

\section{Integrating Semantic Relations}

Edwards (1973), influenced by the writings of Schlesinger, Brown, Slobin and Bloom, attempted to integrate the semantic relationships within a general linguistic system and a cognitive theory to link the semantic relations to the cognitions. He researched the writings of Fillmore, who mainly dealt with trying to arrive at universal categories for adult speakers, and other independent work of linguists with descriptions similar to cases.

Using Brown's (1970) semantic classification of two-word utterances (See Figure 1), Edwards (1973) stated that the classification is still oriented to surface structure and not to underlying meanings. He made three points which support his contention: 1) The relations are classified according to adult grammar (e.g., noun, verb, adjective), much like the pivot-open combinations discussed previously; 2) there was no stated indication that underlying semantic elements may be unexpressed in the utterance as Bloom (1970) considered essential; and 3) no information was given to account for the two term relations being semantically related to each other. Edwards (1973) concluded that until overlapping categories, i.e., cases and terminology describing the cases are standardized, relevance to children's cognition and 
1. Operations of Reference
a. Nominations: that (it or there) + book, cat, clown, hot, big, etc.
b. Notice: hi + mommy, cat, belt, etc.
c. Recurrence: more (or 'nother) + milk, cereal, nut, read, swing, green, etc.
d. Nonexistence: allgone (or no more) + rattle, dog, juice, green, etc.

2. Relations
a. Attributive
Adj. + N (big train)
b. Possessive
$\mathrm{N}+\mathrm{N}$ (Adam checker)
c. Locative
$\mathrm{N}+\mathrm{N}$ (sweater chair)
d. Locative
$\mathrm{N}+\mathrm{V}$ (walk street)
e. Agent-Action
$\mathrm{N}+\mathrm{V}$ (Adam put)
f. Agent-object $\mathrm{N}+\mathrm{N}$ (mommy sock)
g. Action-object $\mathrm{V}+\mathrm{N}$ (put book)

Figure 1. Brown's (1970) semantic classification of twoword utterances.

language will be difficult.

Edwards (1973), following Brown's and Slobin's work, then concerned himself with the common boundary between universal semantic relations and universal sensory-motor cognitions, which converge in the content and process of language in two-word utterances. Brown (1970) and Slobin (1970) stressed the universality of semantic relations and postulated these seem to be extensions of sensory-motor intelligence named by developmental psycholinguist, Jean Piaget. Piaget and Inhelder (1969) viewed language evolving from symbolic function represented by a verbal code as an important aspect of intelligence during 
the second year of life. Furthermore, semantic relations appeared to reflect the child's emerging ability to use words to symbolize objects and events which may or may not be present during the verbalization, as well as to communicate the knowledge and understanding the child has about these objects and events during the sensory-motor stage. Sinclair-de Zwart (1973) contends that the closest link between 1 anguage and intelligent activity relative to a child's environment is found during the very early periods of language learning. He concluded that because of this Piaget's analyses of cognitive structures will be a great help in answering questions about the nature of language.

Using the work of Piaget and Slobin and Brown, Edwards (1973) attempted to present a general framework of semantic relations to describe child language. He discussed case relations of agent, instrument, object, experiencer, phenomenon, location, source and goal, possessor, beneficiary and result. He continued by describing clause types that determine the relations between two-word combinations. The clause types consisted of a single verb with associated case relations. He stated two reservations about the use of this framework for explaining the language a child uses: 1) It may be attributing to the child a too sophisticated model of relations and 2) if the child does possess such concepts, what evidence tells us what these spoken utterances actually mean.

These questions were pursued in the second section of Edwards' (1973) article. In order to draw conclusions about the child's sophistication of semantic relationships and what they mean, he used the sensory-motor cognitions described by Piaget and paralleled these with 
the framework of clause types. The concepts of object, space, causa1ity and time were used as four interrelated aspects of sensory-motor intelligence. Object permanence held a central position in which the aspects of objects, space, causality and time were brought together into a general picture. Figure 2 shows possible links between cognitions and semantic relations. The chart should be read horizontally with causes and actions linked with the semantic relations of agent and causative action or instrument and causative action. The lower half of Figure 2 depicts constants or states and relations coinciding with the semantic relations in the lower right section.

\section{DEVELOPMENTAL SENTENCE ANALYSIS}

Another form of analysis of early child language acquisition and development, i.e., Developmental Sentence Analysis, was established by Lee $(1966,1974)$. Developmental Sentence Analysis has two subsystems, Developmenta1 Sentence Types and Developmenta1 Sentence Scoring. The use of Developmental Sentence Types is a systematic way of looking at the language of a child whose speech is predominantly presentences (A sentence contains a noun and a verb). Lee (1974) has used this approach for describing children's language because other systems such as pivot-open grammars were unsuccessful in describing the variety of language a child uses. Developmental Sentence Scoring describes child language at a more mature level and is a means of analyzing sentences. Developmental Sentence Analysis was created to evaluate children with atypical speech and language in the areas of phonemics, semantics, syntax and morphology. Used as a tool for viewing a child with nor- 
ROLES IN

CAUSATIVITY

\section{AND}

ACTIONS

ROLES IN STATES AND RELATIONS

\section{COGNITIONS}

Psychological causer (role of persons as initiators and causers of events)

Physical causer (role of object or person's body in affecting another object)

\section{SEMANTIC RELATIONS}

Agent

+ causative actions

Object that is in a particular state or relation or undergoing change, movement or the effects of action

1. Spatial locativity of objects

2. Privileged access of persons to objects

3. Persons receiving in hand-to-hand exchanges

4. Persons and their body parts

5. Perceptual discriminada of behavioral importance

\section{LOCATIVE + Location/Source/Goal}

V. perm. POSSESSIVE + Possessor

V. caus. trans. POSSESSIVE + Beneficiary

V. inal. POSSESSIVE + Possessor

V. ATTRIBUTIVE

Figure 2. Summary of links between sensory-motor cognition and language (Edwards, 1973). 
mally developing speech structures, the established and emerging structures of the child can be depicted.

Developmental Sentence Types (DST) were originated to distinguish the different kinds of "sentences" showing varied semantic contents, information and messages. The use of the DST chart (See Appendix A) was not developed to treat the two-word combinations in pivotopen constructions, but to assess the groundwork of emerging sentence types (Lee, 1974). The DST chart has both horizontal and vertical significance. The vertical axis is divided into three areas: single words, two-word combinations and multi-word constructions, which are not complete sentences. The horizontal axis is divided into ten areas: five for single words and five for two-word combinations and multi-word constructions. The horizontal classification determines whether the child is developing a variety of sentence types.

Single words are separated into nouns (e.g., car, truck, mommy), designators (e.g., here, there, this), descriptive items (e.g., big, pretty, more), verbs (e.g., sleep, walk, fall) and vocabulary items (e.g., yes, no, night-night). Two-word combinations and constructions are separated into noun elaborations (e.g., a car, big car, more trucks), designative elaborations (e.g., here truck, this car, what this), predicative elaboration (e.g., T.V. on, where car, that pretty), verbal elaborations (e.g., hit ball, eat cookies, wanna go) and fragments (e.g., for daddy, up now, a11gone).

Lee (1974) has compared the use of Developmental Sentence Analysis with Brown's (1973) grammatico-semantic relationships. She concluded that semantic information can be extracted from a DST classifi- 
cation if the investigator is knowledgeable in relating what the child says to specific semantic relations and sentence type classifications. The comparison of the two systems, grammatico-semantic relationships and Developmental Sentence Analysis, in evaluating language development at the two-word stage has not been researched. Both systems, however, have been used separately to describe children's language at Stage II of language development (Brown, 1973). 
CHAPTER III

RESEARCH PROJECT DESIGN

SUBJECT

The subject for this research project was a female child twentythree months of age, and at the time of the investigation was the first and only child. Her family lived in a residential area in southwest Portland, Oregon. The child's father, a lawyer, is employed with a firm in downtown Portland. Her mother, also a college graduate, was employed part-time with Pacific Northwest Bell. The home environment was very stimulating for language experiences. Some of the mother's close acquaintances were speech and language clinicians, which appeared to make her awareness of language acquisition and development much greater than the average mother.

\section{PROCEDURES}

A spontaneous language sample of the child was collected on ten different days over a period of nine weeks in the child's home with the mother present. During the ten days 1,050 utterances were recorded. A11 language samples were obtained during the morning hours starting at breakfast time, around $9: 30$, and terminating by lunch time or around 12:30. No afternoon language samples were obtained because the child took long afternoon naps. Reasons for terminating each session were dependent on the child, such as showing irritability or 
sickness, or time for lunch.

The investigator remained the observer-transcriber and did not seek interaction with the child. If such interaction did occur, the investigator casually commented or repeated the child's utterance.

For each utterance the investigator recorded on paper a transcription of preceding verbal context, an expansion or interpretation by the observer of the child's utterance and the environmental or situational cues on which the utterance was based (Greenfield and Smith, 1976). Everything the child said was transcribed, except for non-language sounds. Both the mother's and investigator's interpretations were noted when there was conflict of meaning. A replica of the recording form appears in Appendix B.

Additionally, the investigator repeated into a tape recorder the child's utterances and investigator's interpretation of the utterances. Taping allowed for completion and correction of the written transcription at a later time.

\section{EVALUATION INSTRUMENTS}

A Panasonic portable tape recorder was utilized in recording the language samples due to its lightness and easy concealment from the subject.

Developmenta1 Sentence Analysis (Lee, 1974) was used to analyze the recorded and transcribed language samples. According to Lee (1974), Developmental Sentence Analysis is a "method for making a detailed, readily quantified and scored evaluation of a child's use of standard English grammatical rules." DSA encompassed two major divisions, 
Developmental Sentence Types and Developmental Sentence Scoring. Both systems were used due to the subject's sentence length and complexity in the transcribed utterances. (See Appendices A and C.)

Mean length of Utterance (MLU) (Brown, 1973) rules were used to calculate the subject's length of utterance in the transcribed language samples. The focus of attention centered around Brown's Stage II representing an MLU of 2.0-2.75 and described as Modulation of Meaning within the Simple Sentence. The rules for calculating MLU in this clinical project were as follows:

1. Only fully transcribed utterances were used; however, portions of utterances, entered in parentheses to indicate doubtful transcription, were used.

2. Included were all exact utterance repetitions. Stuttering was marked as repeated efforts at a single word; and the word was counted once in the most complete form produced. If a word was produced for emphasis (e.g., no, no, no), each occurrence was counted.

3. Fillers such as "mmm" or "oh" were not counted, but "no, yeah, and hi" were counted.

4. A11 compound words (two or more morphemes), proper names and ritualized reduplications counted as single words. Examples are: birthday, night-night. Justification is that no evidence shows that the constituent morphemes function as such for these children.

5. Counted as one morpheme were all irregular pasts of the verb (e.g., got, did, went, saw). There appears to be no evidence a child relates these to the present forms.

6. Counted as one morpheme were all diminutives (doggie, mommie) because these children at least do not seem to use the suffix in a productive fashion. These diminutives are the standard forms used by the child.

7. Counted as separate morphemes were all auxiliaries (e.g., is, have, will, can, must, would), and also all catenatives (gonna, wanna, hafta). These are counted as single morphemes rather than as going to or want to. Counted as separate morphemes were all inflections (e.g., 
possessive (s), plural (s), third person singular (s), regular past (d), progressive (in)).

8. The total range count followed the above rules but was calculated for the total transcription, not just the individual sessions.

Grammatico-semantic relationships (Brown, 1973; and Schlesinger, 1974) were used for classifying the two-word utterances in the corpus of language. These categories were revised somewhat and used in a recent study comparing the quantity and quality of grammatico-semantic relationships in normal and language-impaired children at Stage I (Freedman and Carpenter, 1976).

The first three categories represent the basic operations of reference, as found previously in Figure 1. They are:

1. Introducer and Entity is presented when a child identifies a referent by naming it. An example is "this car" where "this" represents the introducer and "car" the entity or referent.

2. More and Entity refers to the child asking for recurrence of a thing, a person, or a process of some kind. Examples of the More and Entity relation are "more banana," "'nother man," "more tickle."

3. Negation and Entity has three subcategories. They are: a) nonexistence, e.g., "allgone cookie"; b) rejection, e.g., "no bye-bye"; and c) denial, e.g., "no green."

The next seven categories defined the relations between agents, actions and objects.

1. Agent-Action relations refer to someone or something who initiates an action or process and that action involves any movement. Examples are "daddy work," "dog bark." Brown (1973) found these to be universal at Stage I of language development.

2. Action-object relations refer to a movement or process with someone or something receiving it. Examples are "eat raisin," "wash dollie." Brown (1973) found this to be universal at Stage I. 
3. Agent-Object relations refer to direct interaction between people and/or things. Examples are "mommy purse" and "dog bone." Brown (1973) found this relation to be marginal.

4. Action-Locative relations refer to movement either intended or occurring in a particular space. Brown (1973) found this relation to be marginal at Stage I.

5. Entity-Locative relations refer to someone or something having a separate existence and existing in a specified space or location. Examples are "raisin floor." Brown (1973) found this relation to have stronger occurrence.

6. Possessor-Possession relations refer to someone or something specified as the owner of someone or something. Brown's (1973) data showed this relation to be very frequent at Stage I. Examples are "daddy truck," referring to a truck belonging to daddy, and "baby sweater," referring to the baby's sweater.

7. Entity-Attribute relations refer to something or someone specified by a specific quality or attribute.

Brown (1973) found this to be among the most reliably reported meanings in Stage I. Examples are "big dog" and "old chair."

The following rules were added in order to classify utterances

according to the grammatico-semantic relationships (Brown, 1973;

Slobin, 1973; and Freedman and Carpenter, 1976).

1. Categories were defined semantically instead of grammatically; therefore, word order was not important. As long as meaning could be derived from context, the utterance was appropriately classified.

2. Using "here" and "there" in first or final position was interpreted to mean location as long as there was sufficient non-1inguistic context to interpret a notion of location.

3. Prepositions such as "in," "on," "off" in a context of intended action were interpreted as conveying action. 
LANGUAGE SAMPLE ANALYSIS

Analysis of the language sample was accomplished by using grammatico-semantic relationships (Bloom, 1970; Brown, 1970, 1973; and Schlesinger, 1974), Developmental Sentence Analysis (Lee, 1974) and Mean Length of Utterance (MLU) (Brown, 1973).

Only utterances having sufficient contextual information for later interpretation were used in the analysis. Following Greenfield's (1976) procedure, the following types of utterances were excluded from the analysis:

1. Unintelligible utterances. Those utterances and exclamations with no phonetic shape close to an adult word to allow for interpretation.

2. Uninterpretable utterances. Isolated words from "out of the blue" with no discernible link with the surrounding context.

3. Imitations of preceding statement(s) with no nonverbal evidence of comprehension.

The grammatico-semantic relationships used for analysis of the remaining language sample are 1 isted, with examples and descriptions under Evaluation Instruments.

A restricted use of MLU was utilized as term of reference for developmental level because of its sensitivity in detecting change in early language development.

Developmental Sentence Analysis (DSA) was utilized as part of the study in order to systematically study and evaluate the grammatical development of a child. Developmental Sentence Types (DST) were specifically used to assess grammatical development of a child predominantly speaking in presentences. 
The investigator recorded the percentages of each grammaticosemantic relationship expressed for each session.

After each utterance was analyzed, using both the grammaticosemantic and Developmental Sentence Analysis, a check sheet was used to evaluate which system provided more descriptive information or if there was duplication of information using both systems. The checklist also was used to assess the efficiency of one system over the other system. 
CHAPTER IV

RESULTS AND DISCUSSION

\section{RESULTS}

The purpose of this clinical research project was to analyze a corpus of expressive language emitted by a child at the two-word stage of language development. The project was conducted on 10 different days, with sessions lasting from $1 \frac{1}{2}$ hours up to $3 \frac{1}{2}$ hours of language sample collecting, totalling $24 \frac{1}{2}$ hours of data collection. Table I shows the period or session number, age of the child in months and days, duration of each session in hours and minutes, total number of utterances recorded during each session and a calculated MLU for each session.

Analysis of the language sample was completed using three measures. Grammatico-Semantic Relationships (Brown, 1973; Schlesinger, 1974; and Freedman and Carpenter, 1976) were utilized to gain information pertaining to a child's semantic level of language development and how words at the two-word stage interrelated. The second instrument used for analysis was Developmental Sentence Analysis (Lee, 1974). This tool provided a means to analyze both single and multiword utterances. The third type of analysis was completed using Brown's (1973) instructions for calculating Mean Length of Utterance (MLU). This measurement provided the investigator a means to detect sma11 increments of change in terms of utterance length. 
TABLE I

SCHEDULE OF CHILD'S OBSERVATION SESSIONS

\begin{tabular}{ccccccc}
\hline Session & \multicolumn{2}{c}{ Age } & \multicolumn{2}{c}{ Duration } & $\begin{array}{c}\text { Total \# } \\
\text { Utterances }\end{array}$ & MLU \\
& Mths. Days & Min. & Utters \\
II & 23 & 0 & 2 & 30 & 53 & 1.92 \\
III & 23 & 2 & 2 & 30 & 53 & 2.08 \\
IV & 23 & 15 & 3 & & 99 & 2.03 \\
V & 23 & 22 & 3 & & 43 & 2.14 \\
VI & 23 & 23 & 2 & 30 & 124 & 2.18 \\
VII & 24 & 6 & 2 & & 39 & 1.78 \\
VIII & 24 & 7 & 2 & 30 & 94 & 1.89 \\
IX & 24 & 20 & 3 & 30 & 279 & 1.87 \\
X & 24 & 21 & 1 & 30 & 129 & 1.83 \\
\hline
\end{tabular}

Grammatico-Semantic Analysis

Performance of the child was analyzed using grammatico-semantic relationships (Brown, 1973; Freedman and Carpenter, 1976; and Greenfield, 1976). The following grammatico-semantic relationships were utilized in the analysis: Introducer and Entity ( $I+E)$; More or Recurrence and Entity $(M+E)$; Negation and Entity $(N+E)$; Agent and Action $(A G+A C)$; Action and object $(A C+O B)$; Agent and object $(A G+O B)$; Action and Locative $(A C+L)$; Entity and Locative $(E+L)$; Possessor and Possession $(P+P)$; and Entity and Attribute $(E+A)$. The percentage of occurrence of these relationships for each session may be found in Table II. 
TABLE II

PERCENTAGE OF GRAMMATICO-SEMANTIC RELATIONSHIPS FOR EACH SESSION

\begin{tabular}{rcccccccccc}
\hline Session & $\begin{array}{c}\text { I+E } \\
\%\end{array}$ & $\begin{array}{c}\mathrm{M}+\mathrm{E} \\
\%\end{array}$ & $\begin{array}{c}\mathrm{N}+\mathrm{E} \\
\%\end{array}$ & $\begin{array}{c}\mathrm{AG}+\mathrm{AC} \\
\%\end{array}$ & $\begin{array}{c}\mathrm{AC}+\mathrm{OB} \\
\%\end{array}$ & $\begin{array}{c}\mathrm{AG}+\mathrm{OB} \\
\%\end{array}$ & $\begin{array}{c}\mathrm{AC}+\mathrm{L} \\
\%\end{array}$ & $\begin{array}{c}\mathrm{E}+\mathrm{L} \\
\%\end{array}$ & $\begin{array}{c}\mathrm{P}+\mathrm{P} \\
\%\end{array}$ & $\begin{array}{c}\mathrm{E}+\mathrm{A} \\
\%\end{array}$ \\
\hline I & 16.98 & 0 & 1.89 & 9.43 & 9.43 & 1.89 & 1.89 & 5.66 & 5.66 & 5.66 \\
II & 9.43 & 0 & 7.55 & 7.55 & 7.55 & 1.89 & 0 & 5.66 & 13.20 & 9.43 \\
III & 9.09 & 8.08 & 2.02 & 9.09 & 18.18 & 7.07 & 3.03 & 2.02 & 5.05 & 9.09 \\
IV & 9.30 & 13.95 & 6.98 & 2.33 & 16.28 & 2.33 & 4.65 & 6.98 & 0 & 6.98 \\
V & 7.91 & 7.19 & 4.32 & 5.75 & 15.38 & 4.32 & 3.69 & 2.88 & 5.04 & 9.35 \\
VI & 6.45 & 3.23 & 1.61 & 3.23 & 12.90 & 1.61 & 1.61 & 5.64 & 8.06 & 11.29 \\
VII & 5.40 & 8.11 & 0 & 8.11 & 16.22 & 2.70 & 2.70 & 5.40 & 8.11 & 8.11 \\
VIII & 4.25 & 0 & 0 & 6.38 & 27.66 & 0 & 1.06 & 2.13 & 2.13 & 11.70 \\
IX & 2.87 & 4.30 & 1.43 & 2.15 & 23.66 & 3.23 & 2.87 & 2.15 & 5.38 & 6.09 \\
X & 9.30 & 0 & 0 & 4.65 & 13.95 & 4.65 & 3.88 & .78 & 9.30 & 10.85 \\
\hline
\end{tabular}


During Session I the child was 23 months of age. In the $2 \frac{1}{2}$ hour session 53 utterances were recorded, with MLU calculated at 1.92 . In viewing the relationships, the Introducer and Entity category showed the highest frequency of occurrence with 16.98 percent of the total number of utterances collected during that session. Agent-Action and Action-object relationships were equal in representation with 9.43 percent. The More and Entity category did not occur during this first session. The percentage of single-word utterances was 24.52 , but these were not scored using this system. Utterances with 3 or more words comprised 15.09 percent of the first session's 53 utterances. These also were not analyzed using this system.

Session II, age 23 months, 2 days, showed Possessor and Possession with highest frequency of occurrence for 13.20 percent of the 53 utterances falling within this category. No Recurrence and Entity or Action and Location relationship was recorded. There was an increase in the amount of Negation and Entity relations from Session I, but a decrease in Introducer and Entity relations from Session I. MLU was calculated at 2.08 . There were 15 one-word utterances and 4 threeword-plus utterances recorded, comprising 28.30 percent and 7.55 percent respectively. One utterance was uninterpretable during Session II.

At 23 months, 15 days of age during Session III, 99 utterances were recorded from the subject. MLU was calculated at 2.03. One-word utterances comprised 21.21 percent of the total and 5.05 percent threeor-more-word utterances. Again, as in Session II, one utterance was excluded. In percentages of grammatico-semantic relationships, Action 
and object relations were of highest frequency at 18.18 percent with Negation and Entity and Entity and Location low at 2.02 percent. The More or Recurrence and Entity relationship occurred for the first time over the three sessions, with a total of 8.08 percent of the 99 utterances falling within this category.

During Session IV, age 23 months, 16 days, only 43 utterances were collected. The session lasted on 1 y $1 \frac{1}{2}$ hours due to the irritability of the subject. MLU was calculated at 2.14. On this day Action and $\mathrm{object}$ and More and Entity relationships were more frequent, with 16.28 percent and 13.95 percent respectively of the total utterance count. No utterances fitting the guidelines for Possessor and Possession were recorded. It should be noted that over the four sessions already discussed the categories of Introducer and Entity and Entity and Attribute remained approximately the same. The relationship Agent and Action decreased in this session compared to previous sessions. There also appeared to be a gradual increase in Action and Location relationships from Session I to Session IV. There were 6 one-word utterances recorded for 13.95 percent and 6 three-or-more-word utterances for 13.95 percent of the total. One utterance was excluded. Session V, age 23 months, 22 days, lasted 3 hours. During that time 139 utterances were recorded. MLU increased to 2.19 and all categories were represented in the sample. Action and object utterances were more frequent at 15.83 percent. There were 25 one-word utterances for 17.99 percent and 20 three-or-more-word utterances at 14.39 percent. One utterance was excluded due to insufficient situational cues. 
At 23 months, 23 days of age, during Session VI, 124 separate utterances were collected, with an MLU of 2.18. There was an increase in one-word utterances, with 33.06 percent falling within this category. Only 8.87 percent of the total were three-or-more-word utterances. Three utterances were uninterpretable. There were increases in frequency of occurrence in Possessor and Possession relations and Entity and Attribute relations over the previous session. Action and Object utterances occurred more often at 12.90 percent; and Negation and Entity, Agent and Object, and Action and Location relationships each represented 1.61 percent of the total 124 utterances.

The lowest number of total utterances for a session was collected during Session VII; only 37 utterances were obtained from the child while in the home environment. A trip to the park was planned and utterances could not be accurately recorded once we left the home. Calculated MLU was 1.78. Four categories had equal representation at 8.11 percent. They were More and Entity, Agent and Action, Possessor and Possession, and Entity and Attribute. The most frequent relationship was again Action and Object with 16.22 percent of the total sample. A high 32.43 percent of the utterances were single-word utterances. Only one utterance had 3 words.

Session VIII consisted of 94 utterances. The child's age was 24 months, 7 days. MLU was calculated at 1.89. Three categories were not represented at all during this session. They were More and Entity, Negation and Entity, and Agent and object. Action and object showed the largest representation with 27.66 percent of the utterances falling within it. One-word utterances comprised 32.98 percent of the total 
and 7.45 percent were three-or-more-word utterances. Three utterances were uninterpretable.

Session IX comprised the largest number of utterances recorded during any single session. During $3 \frac{1}{2}$ hours 279 utterances were collected. The child, now 24 months, 20 days old, expressed utterances represented under the 10 categories. Action and object utterances at 23.66 percent were the most frequent relationships used with Negation and Entity showing the lowest frequency at 1.43 percent. One-word utterances increased to 42.29 percent, which affected the MLU calculated at 1.87. Nineteen three-or-more-word utterances at 6.81 percent representation were recorded and 5 utterances were excluded.

The final session, at which time the child was 24 months, 21 days old, lasted approximately $1 \frac{1}{2}$ hours. MLU was calculated at 1.83 for the 129 separate utterances collected. One-word utterances comprised 37.21 percent of the total utterances and 3.86 percent of the utterances were 3 or more words. Five utterances were uninterpreted. Action and object, Entity and Attribute, Possessor and Possession, and Introducer and Entity showed the highest percentages with $13.95,10.85$, 9.30 and 9.30 percent respectively. Two categories were not represented. These were More and Entity and Negation and Entity. The Grammatico-Semantic Relationships Analysis utilized for evaluating the semantic level of language was one measure of analysis.

\section{Developmental Sentence Analysis}

The corpus of expressive language was further analyzed using an instrument designed for viewing language at a grammatical or syntactical level. Using one part of Developmental Sentence Analysis (DSA) 
(Lee, 1974) called Developmental Sentence Types, the child's language sample could be viewed at the presentence level; at this level singleword utterances, two-word combinations and multi-word constructions were examined. When the child generated sentences (i.e., noun and verb constructions), Developmental Sentence Scoring was used to evaluate the structures. Table III shows the total number of single-word, two-word and multi-word constructions for each session, as well as the percentage based on the total number of utterances for each session. Also included in Table III is the total number of utterances from each session which were considered to be sentences (noun and verb) and were thus subjected to analysis using Developmental Sentence Scoring. Over 50 percent of the utterances were classified under two-word combinations.

In viewing Table III the following interesting observations were made. During Session II only 1.89 percent of the utterances were multi-word constructions (three or more words) and only 2.02 percent were multi-word constructions in Session III. Of the total number of utterances for Session III, Developmental Sentence Scoring was used to evaluate 16.16 percent. Session VII showed a decrease in Mean Length of Utterance to 1.78 . During this session the lowest number of utterances was collected. In Session IX, the largest number of utterances in any single session was collected. A large percentage, 41.58 percent, consisted of single words. Two-word combinations were slightly more at 45.16 percent of the total, multi-word constructions represented 6.09 percent and 4.66 percent were analyzed using Developmental Sentence Scoring. 


\section{TABLE III}

PERCENTAGE OF DEVELOPMENTAL SENTENCE TYPES

\begin{tabular}{|c|c|c|c|c|c|c|c|c|c|c|}
\hline Type Utterance & I & II & III & IV & $\underset{v}{s e s} s i$ & $\begin{array}{l}0 \mathrm{n} s \\
\mathrm{VI}\end{array}$ & VII & VIII & IX & $\mathrm{x}$ \\
\hline $\begin{array}{l}\% \text { Single words } \\
\text { Total \# }\end{array}$ & $\begin{array}{l}22.64 \\
12\end{array}$ & $\begin{array}{l}28.30 \\
15\end{array}$ & $\begin{array}{l}21.21 \\
21\end{array}$ & $\begin{array}{c}13.95 \\
6\end{array}$ & $\begin{array}{l}18.70 \\
26\end{array}$ & $\begin{array}{l}32.26 \\
40\end{array}$ & $\begin{array}{l}32.43 \\
12\end{array}$ & $\begin{array}{l}32.98 \\
31\end{array}$ & $\begin{array}{l}41 \cdot 58 \\
116\end{array}$ & $\begin{array}{l}35.66 \\
46\end{array}$ \\
\hline $\begin{array}{l}\% \text { Two-word } \\
\text { combinations } \\
\text { Total 非 }\end{array}$ & $\begin{array}{l}56.60 \\
30\end{array}$ & $\begin{array}{l}52.83 \\
28\end{array}$ & $\begin{array}{l}59.60 \\
59\end{array}$ & $\begin{array}{l}60.46 \\
26\end{array}$ & $\begin{array}{l}53.24 \\
74\end{array}$ & $\begin{array}{l}45.97 \\
57\end{array}$ & $\begin{array}{l}56.76 \\
21\end{array}$ & $\begin{array}{l}53.19 \\
50\end{array}$ & $\begin{array}{l}45.16 \\
126\end{array}$ & $\begin{array}{l}56.59 \\
73\end{array}$ \\
\hline $\begin{array}{l}\% \text { Multi-word } \\
\text { constructions } \\
\text { Total 非 }\end{array}$ & $\begin{array}{c}13.21 \\
7\end{array}$ & 1.89 & $\begin{array}{l}2.02 \\
2\end{array}$ & $\frac{11.63}{5}$ & $\begin{array}{l}10.07 \\
14\end{array}$ & $\begin{array}{l}4.84 \\
6\end{array}$ & $\begin{array}{l}0.0 \\
0\end{array}$ & $\begin{array}{l}6.38 \\
6\end{array}$ & ${ }^{6.09}$ & $\begin{array}{l}2.33 \\
3\end{array}$ \\
\hline $\begin{array}{l}\% \text { Sentences } \\
\text { (noun + verb) } \\
\text { Total \# }\end{array}$ & $\begin{array}{l}7.55 \\
4\end{array}$ & $\begin{array}{c}15.09 \\
8\end{array}$ & $\begin{array}{l}16.16 \\
16\end{array}$ & $\begin{array}{c}13.95 \\
6\end{array}$ & $\begin{array}{l}15.83 \\
22\end{array}$ & $\begin{array}{l}13.71 \\
17\end{array}$ & $\begin{array}{c}10.81 \\
4\end{array}$ & $\begin{array}{l}6.38 \\
6\end{array}$ & $13^{4.66}$ & $\begin{array}{l}3.10 \\
4\end{array}$ \\
\hline
\end{tabular}


Table IV 1ists each division in Developmental Sentence Types and the number of utterances under each division per session. Table IV also shows further breakdown of single words, two-word combinations and multi-word constructions into their constituent structures, as we11 as an overa11 total for each division.

Under single words the largest number of utterances was classified under nouns. The child used many referents (e.g., mommy, daddy, car) throughout the entire project, as may be noted also in the twoword combinations and multi-word constructions. The second largest category was verbs (e.g., work, make, tickle) under single words, with the majority of them appearing in the last three sessions. Few designators were expressed in single-word utterances. Some examples were "this," "that" and "here." Descriptive items (e.g., pretty, hard, cold) were a little more frequent as were vocabulary items (e.g., hi, bye-bye).

Two-word combinations were used for the majority of the language sample analysis. This would be expected when considering the child's MLU ranged from 1.78 to 2.19 . Noun elaborations such as "a baby," "mommy pumpkin" and "more juice" were the largest category used. Verbal elaborations (e.g., wash hands, tickle Lessy, color sack) were the next frequent classification. Designative elaborations (e.g., that yours, doggie there, what this?) and predicative elaborations (e.g., apple off, T.V. out, socks on) were about equal in representation throughout a11 ten sessions. The least represented category under twoword combinations was fragments. Such utterances as "all gone," "up too" and "in there" were classified under fragments. 
TABLE IV

BREAKDOWN OF DEVELOPMENTAL SENTENCE TYPES

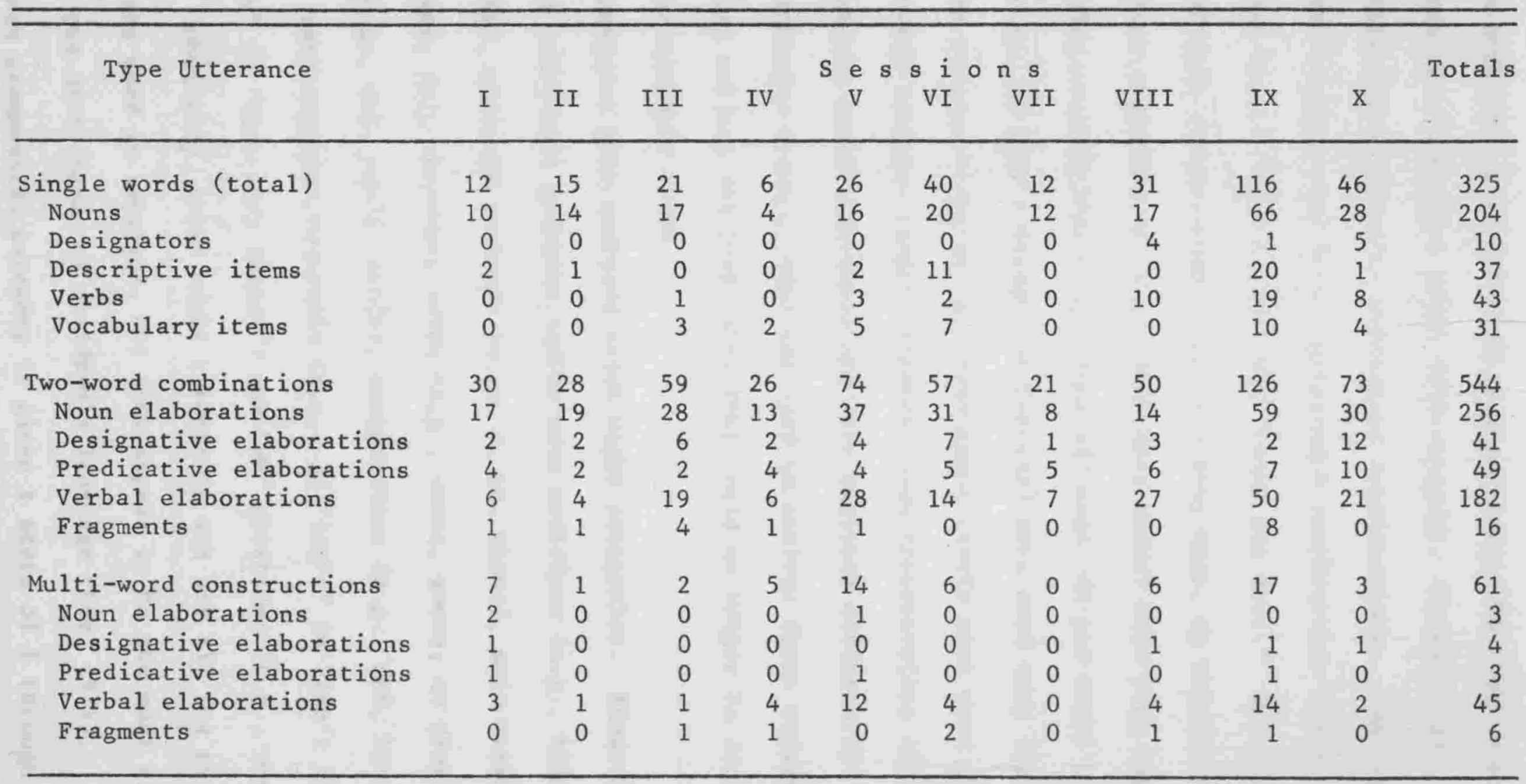


In reference to multi-word constructions, the least number of utterances was classified under this category. Verbal elaborations represented the majority of multi-word constructions. Some examples of the verbal elaborations at the multi-word construction level were "want some face," "make it too" and "close the door." The other categories of noun elaborations (e.g., a pretty mama, my cracker too), designative elaborations (e.g., What this shirt? This your paper), predicative elaborations (e.g., Icky off mama, OK pen down) and fragments (e.g., up papa's house, one-two-six) were used very little.

The constructions at the presentence levels were more frequent in the total language sample; however, some constructions were considered sentence level utterances and were analyzed differently. Developmental Sentence Scoring (DSS) was used to analyze those constructions containing subject and predicates that could no longer be considered at the presentence level.

Sentences were analyzed under eight categories. These categories included indefinite pronouns and/or noun modifiers (e.g., that, this, more, a11), personal pronouns (e.g., I, me, these), main verbs (e.g., go, played, is), secondary verbs (e.g., wanna, gonna, to play), negatives (e.g., not, can't, don't), conjunctions (e.g., and, but, because), interrogative reversals (e.g., as "Isn't" in "Isn't it red?" or "Were" in "Were they there?") and "wh" questions (e.g., who, what, where). Obviously, these eight categories are not all the grammatical structures used in language, but they appear to be the most significant in the development of children's language (Lee, 1974).

Each grammatical category is given a score of 1 through 8 repre- 
senting levels of complexity. If a structure is lacking in some feature required in standard English, an attempt mark is given instead of a numerical score. (Refer to Appendix C.)

In Table V the child's utterances using Developmental Sentence Scoring are represented. This table shows the distribution of points given each utterance analyzed, using Developmental Sentence Scoring; the score is shown in parentheses. The following observations can be made. A score of 1 was given to the majority of grammatical constructions, with main verbs the most frequent form. Some indefinite pronouns and personal pronouns were used in the sentences analyzed. Many sentences were given attempt marks (att) under main verbs primarily because of omissions of verb inflections. Four sentences contained secondary verbs and five contained "wh" questions that were given a score of 2 .

In addition to the eight categories, each sentence also was evaluated on the basis of its correctness of grammar. This factor deals with whether or not the structure is acceptable or adultike. The majority ( 66 percent) of the child's sentences was not acceptable as complete grammatical sentences; however, the 34 percent evaluated as grammatical sentences is a large percentage for a child of this young age.

\section{Mean Length of Utterance}

The third and final instrument of analysis was Mean Length of Utterance (Brown, 1973). Much of this data has been reported previously. Mean Length of Utterance ranged from a low of 1.78 during Session VII to 2.19 in Session V. The average MLU over the ten sessions 
TABLE V

BREAKDOWN OF DEVELOPMENTAL SENTENCE SCORING

\begin{tabular}{|c|c|c|c|c|c|c|c|c|c|c|c|}
\hline \multirow{2}{*}{ Session } & \multirow{2}{*}{ I.P. } & \multirow{2}{*}{ P.P. } & \multicolumn{4}{|c|}{ Grammatica1 Categories } & \multirow{2}{*}{\multicolumn{2}{|c|}{ I.R. }} & \multirow[b]{2}{*}{ Wh-? } & \multirow{2}{*}{ S.P. } & \multirow[t]{2}{*}{ Totals } \\
\hline & & & M.V. & S.V. & Neg. & Conj. & & & & & \\
\hline I & 2 (1) & 0 & $\begin{array}{ll}2 & (\mathrm{att}) \\
2 & (1)\end{array}$ & 0 & 0 & 0 & & 0 & 0 & 2 & 6 \\
\hline II & $1(1)$ & 0 & $\begin{array}{ll}7 & (\mathrm{att}) \\
1 & (1)\end{array}$ & 0 & 0 & 0 & & 0 & 0 & 1 & 3 \\
\hline III & $2(1)$ & 2(1) & $\begin{array}{ll}7 & (a t t) \\
7 & (1) \\
1 & (2)\end{array}$ & $1(2)$ & - & netas & & $=$ & $2(2)$ & 6 & 25 \\
\hline IV & 4(1) & $1(1)$ & $\begin{array}{l}2 \text { (att) } \\
4 \text { (1) }\end{array}$ & 0 & 0 & 0 & & 0 & 0 & 3 & 12 \\
\hline V & $4(1)$ & 0 & $\begin{array}{l}12(\text { att }) \\
10(1)\end{array}$ & $1(2)$ & 0 & 0 & 1 & $(a t t)$ & $3(2)$ & 6 & 28 \\
\hline VI & $\begin{array}{l}1 \text { (1) } \\
1 \text { (3) }\end{array}$ & $\begin{array}{l}2(a t t) \\
2(1)\end{array}$ & $\begin{array}{ll}7 & (\text { att }) \\
9 & (1) \\
1 & (2)\end{array}$ & $1(5)$ & 0 & 0 & & 0 & 0 & 6 & 28 \\
\hline VII & $1(1)$ & $2(1)$ & $\begin{array}{l}3(a t t) \\
2(1)\end{array}$ & 0 & 0 & 0 & & 0 & 0 & 1 & 6 \\
\hline VIII & 2 (1) & 1 (1) & $\begin{array}{ll}1 & (a t t) \\
2 & (1) \\
2 & (2)\end{array}$ & 1 (2) & 0 & 0 & & 0 & 0 & 4 & 15 \\
\hline
\end{tabular}




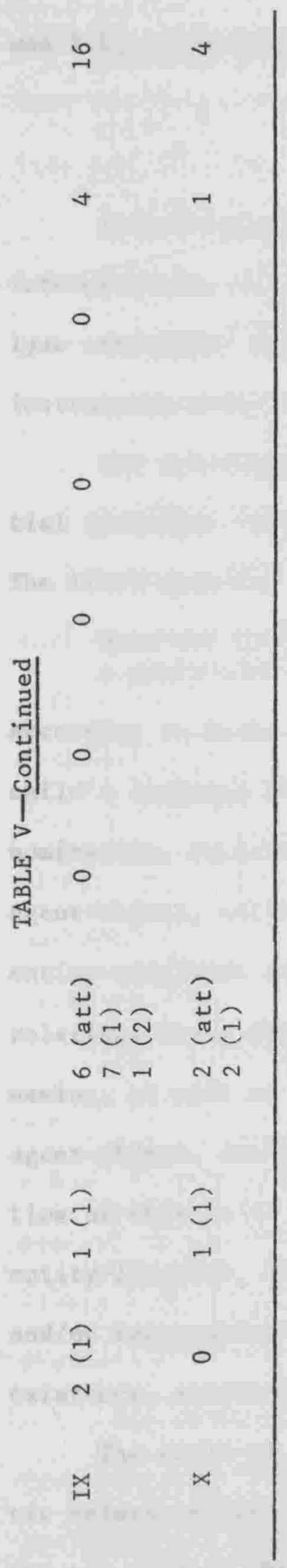


was 2.0, or at Stage II of language development (Brown, 1973).

\section{DISCUSSION}

In consideration of the data presented in the previous sections, interpretation of the findings was made. Each system appeared to analyze utterances slightly different from the other and yet all are instruments utilized in describing children's language.

The development of this clinical project focused on four essential questions relative to the two-word stage of language development. The first question was:

Does the child express grammatico-semantic relations in a particular developmental order?

According to Brown (1973), eleven semantic relations are found in a child's language during Stages I and II. These semantic relations are: nomination, recurrence, nonexistence, agent-action, action-object, agent-object, action-1ocative, entity-1ocative, possessor-possession, entity-attribute and demonstrative-entity. The existence of these relations being expressed by a child appear to show him concerned with naming, as well as identifying, people and objects (i.e., nomination, agent-object, entity-attribute, demonstrative-entity), with the location of objects or people relative to other objects or himself (i.e., entity-locative, possessor-possession) and with the disappearance and/or reappearance of things from his view (i.e., recurrence, nonexistence, action-object).

The child of this clinical research project expressed ten semantic relationships identified in Chapter III. The difference between the ten used in this project and the eleven listed above concerns the 
nomination and demonstrative-entity relations. These were combined into one relation of introducer and entity. Essentially the two systems are the same.

The most frequent semantic relationship was the action-object relationship (See Table II). Throughout each of the ten sessions these structures maintained a high percentage of occurrence relative to a11 relationships expressed.

Introducer-entity and entity-attribute relationships also were expressed frequently during each session. The occurrence of these relationships follows the child's concerns with naming things in the environment and stating some salient features of these things. Brown (1973) found the entity-attribute relation the most reliably reported relationship. More-entity relationships did not occur during four sessions and negative-entity relations did not occur for three sessions. This is not to conclude these were emerging features, as it would be unwarranted to make a broad statement based on the relatively small amount of utterances collected during each session. Agent-action and possessor-possession relationships were represented in equal proportions during the sessions. There appeared to be a high correlation between the occurrence of these relationships expressed in this investigation with Brown's (1973) reports on the relatively high frequency of occurrence of agent-action and possessorpossession relationships.

The action-locative relations that Brown (1973) and Freedman and Carpenter (1976) found to be marginal in occurrence also were relative$1 y$ infrequent in this investigation. Entity-locative relationships 
did, however, occur with higher frequency in this project.

The grammatico-semantic relationships of the child in this project appeared to follow a developmental order according to what has been reported by Brown (1973), Lee (1974) and Freedman and Carpenter (1976).

The second question was:

Do new grammatico-semantic relationships emerge as MLU increases in the language sample?

On a quantitative basis the emergence of new grammatico-semantic relationships was difficult to assess. Table II showed that during Session I all ten relationships were represented except the more-entity relationship. The Mean Length of Utterance was 1.92 or just emerging into Stage II (Brown, 1973). All utterances were analyzed using the grammatico-semantic analysis, meaning no higher level or complex relationships were found. As MLU increased to 2.08 in Session II, there was an increase in the percentages of occurrence for the following relationships: negative-entity, possessor-possession and entityattribute. There were however, no utterances categorized under moreentity or action-location relationships and there was a decrease noted in the frequency of introducer-entity relationships.

In Session $\mathrm{V}$ the highest MLU was calculated to be 2.19. A11 semantic relationships were represented. Three utterances were not interpreted in this session according to the grammatico-semantic analysis. Two were excluded from the total due to insufficient context and the third showed a conjunctive relationship not found in the ten relationships used in this study. 
On a quantitative basis, the relationships represented with the highest frequency were concerned with naming common objects or people in the environment and how these people or objects interacted with the environment. Perhaps the qualitative differences that occurred from Session I to Session $\mathrm{X}$ were significant. As the language sample collecting progressed, the child became more comfortable with the presence of the investigator. There was less and less reticence to talk as each session progressed. Another factor with possible influence was the mother's contribution to the collection of the child's language. As the project progressed, she also became more comfortable and found it easier to carry on with her daily activities as planned.

The third question was:

What are the demonstrated differences between using both the grammatico-semantic relationships and Developmental Sentence Analysis?

The first major difference observed was analyzing the single-word utterances. Grammatico-semantic relationships could not be used because they are used to explain how two or more words interrelate. On the other hand, Developmental Sentence Types were used to evaluate not only the two-word combinations, but also single-word and multi-word constructions. Since the child's MLU averaged 2.0, many single words were used and needed to be analyzed. In multi-word constructions, Developmental Sentence Types were again used. These constructions were not analyzed using grammatico-semantic relationships for this investigation; however, such relationships could be adapted to multiword constructions with little difficulty and would represent more complex structures. 
Another major difference concerning the semantic versus syntactic level of language development was one this investigator expected to find. Word order was not an important factor when evaluating the utterances using grammatico-semantic analysis. Most of the utterances did follow the standard adult syntactical order (i.e., agent-action, action-object), but some of the utterances did not. It was easier to evaluate utterances using grammatico-semantic relationships when they did not follow adult syntactical order than when assessing the same structures using Developmental Sentence Types.

Developmental Sentence Analysis (Lee, 1974), utilizing both Developmental Sentence Types and Developmental Sentence Scoring, presented a picture of the child using her native language in a range from single words to "adultlike" sentences. The combination of a noun and a verb under grammatico-semantic analysis was analyzed as an agentaction relationship, but was scored according to Developmental Sentence Scoring format (higher grammatical level) as opposed to the Developmental Sentence Types categories. Using the DSS procedure for some of the utterances appeared to show more of a progression into mature structures than was expressed by the grammatico-semantic relationships procedure.

The fourth and final question was:

Does one system of analysis provide more information at one point of language development than the other?

In viewing the two measures used in this clinical research project, Developmental Sentence Analysis appeared to provide more information than did the use of grammatico-semantic relationships. The design of the DST enabled the investigator to analyze grammatical categories 
(e.g., nouns, descriptors, verbs) and also the morphologically significant factors of plurals, possessives and tense markers. From a clinical viewpoint, this type of information is vital and can be obtained using Developmental Sentence Analysis. On the other hand, from a theoretical point of view, to know how and why a child combines certain words into semantic relationships is also important (Schlesinger, 1971; and Brown, 1973).

Using grammatico-semantic relationships in explaining the twoword stage of language development appeared inadequate, The period of language development when a child combines two words is relatively brief; and with the presence of single words and emerging multi-word structures, using a system designed for a specific time period is not a very economical system. Many of the relationships overlapped and care had to be taken to examine the situational cues in order to make a decision on a specific utterance. It would have been easy to assign a relationship that was too advanced for what the child was actually expressing due to adult bias on the part of the examiner. Although the majority of the utterances could be assigned a relationship, it was not uncommon for this examiner to reclassify, over and over again, the same utterance in attempting to see the situation from a child's viewpoint. Since Developmental Sentence Analysis is based on a syntactical format and is a more "adultlike" system, assigning utterances using DSA was an easier task. Lee (1974), combining many theories of language development, developed a unified structure; whereas, grammaticosemantic relationships have differed from researcher to researcher. Terminology was not standardized and interpretations of the salient 
features of the two-word stage of language development were varied (Bloom 1970; Schlesinger, 1971; and Brown, 1973).

Using a semantic analysis did give a richer evaluation of the child's language (Bloom, 1970) than a grammatical analysis (i.e., DST and/or DSS) did alone.

Lee (1974) found semantic information could be interrelated with the DST material. The original DST chart (See Appendix B) was amended (Lee, 1974) using the semantic relations discussed by Brown (1973) (Refer to Appendix D). Under designative sentence, Column 2 of the DST, the semantic relations of nomination and demonstrative-entity are classified. The predicative sentence, Column 3, relates to entitylocative and entity-attribute relations. The subject-verb sentence is found in Column 4. Agent-action, action-object and action-location are categorized under this. The noun phrase adapts the relations of nomination, agent-object and entity-locative.

The next group of semantic categories was scattered due to many grammatical representations. Possessor-possession relationships could be classified under Column 1. Possessor-possession relationships were either noun phrases or pronouns. Recurrence relations could be represented under the noun phrase, Column 1, the designative phrase, Column 2 , the predicative phrase, Column 3 , or the verbal phrase, Column 4 . The nonexistence relationship also is scattered on the DST chart. A11 negative constructions were found at the bottom of each column and it would depend in the situational cues what category was appropriate. Being able to use the DST format and interpolating semantic relationships into it made the DST a more flexible instrument and thus 
aided the investigator in answering question four by concluding that using Developmental Sentence Analysis provided more information over the ten sessions than the grammatico-semantic relationships did. Both systems required the investigator to depend on contextual information when deciding how each utterance was to be classified; but overall analysis was easier using DSA because of its structure than the more theoretical grammatico-semantic relationships analysis.

Some comment needs to be made concerning the rise of the MLU from Session I to Session VI, and the decrease in MLU from Session VII to Session $\mathrm{X}$. The investigator can only speculate as to the rise and fall of MLU over the ten sessions. The parents of the child were expecting their second baby within weeks after termination of this study; and the child may have been reacting to the approaching birth.

Also, the Christmas season was approaching and the new experiences it brought may have affected the amount of language output. The child may not have had the words to express her thoughts and feelings. She also was experiencing some intermittent colds throughout the data collection and showed signs of irritability consisting of crying and tiredness.

Another observation, made after the data collection, is the possibility that if more days of data collection had occurred, perhaps the MLU results may have been altered in that MLU would have increased and stabilized in Stage II (Brown, 1973) with the added observation time. 
CHAPTER V

SUMMARY AND IMPLICATIONS

\section{SUMMARY}

The purpose of this clinical project was to subject a corpus of expressive language at the two-word stage of language development to analyses. The child's language used in this research project could be classified at Stage II (Brown, 1973). The language sample was analyzed using three measures of language development: grammaticosemantic relationships, Developmental Sentence Analysis and Mean Length of Utterance.

The results of this project revealed that the child expressed the ten semantic relationships established by Brown (1973), as well as the grammatical categories designated in Developmental Sentence Analysis. Mean Length of Utterance averaged 2.0 during the ten sessions comprising the corpus.

The child expressed semantic relationships at percentages of occurrence correlating with the finding of Brown (1973), Lee (1974) and Carpenter and Freedman (1976).

The child's one-, two-, three-or-more-word utterances were analyzed using Developmental Sentence Analysis (DSA) consisting of two systems: Developmental Sentence Types (DST) for presentences and Developmental Sentence Scoring (DSS) for those utterances classified as sentences. DSA enabled the investigator to evaluate the syntacti- 
cal growth of the child.

Mean Length of Utterance was helpful in detecting small increments of change in her language (i.e., plurality, possessive and tense markings).

Grammatico-semantic relationships attempt to describe a level of language that is little understood. A semantic analysis of language during early language development appears to be an important area of concern. Since the child uses so few words to express his interpretations of the environment around him, syntactical analysis cannot always describe language completely. DSA attempts to interrelate semantic interpretation into its syntactical format to make rich interpretation possible. For this reason, DSA was a more flexible tool for analyzing this child's language at the two-word stage.

\section{IMPLICATIONS}

\section{$\underline{\text { Clinical }}$}

The three systems used in this project have been used in research settings, but the investigator is uncertain as to the frequency of use of grammatico-semantic relationships in the clinical setting. Clinically, MLU has been used for a longer period of time, but other measurements need to accompany it in order to obtain a complete picture of a child's 1anguage.

To assess semantic and syntactic levels can be accomplished by using both systems (i.e., grammatico-semantic analysis and Developmental Sentence Analysis). Time factors do not always allow for an indepth look at children, especially in a public school setting, but 
with practice in obtaining and analyzing language samples, the speech and language pathologist can obtain information vital to clinical teaching goals. Based on this project the investigator suggests using both systems of grammatico-semantic relationships and DSA for a richer evaluation of a child's language level. DSA has normative data that can aid in what a speech clinician can do toward language management, but normative data should be collected within the region where the child lives before specific information on language development is valid and reliable.

A longitudinal study using one child enabled the investigator to develop skills in judging language interactions with mother and child, to view and evaluate the child's utterances on a "childlike" level as opposed to an "adultlike" level, to observe the child with her mother, as we1l as this investigator, to understand the wants and needs she expressed and, finally, to see the growth of language and its complexity over time.

\section{$\underline{\text { Research }}$}

At the present time there are no universally accepted case grammars. Adaptations made of Fillmore (1968), Chafe (1970), Bloom (1970), Schlesinger (1971) and Brown (1973) could be made in order to combine all the findings of these researchers. Normative data could then be collected on differing populations (e.g., normal, language impaired, hearing impaired, bilingual children) in order to obtain more definitive guidelines for use.

Over an extended period of time a longitudinal study could be developed to compare later development of grammatico-semantic relation- 
ships to early development of these relationships. This could be accomplished by using one child or using two children, one at Stage II and one at Stage III of language development (Brown, 1973).

A final thought is research into a semantic-based teaching program compared to a syntax-based teaching program used with languagehandicapped children. Results may indicate one system is better than another, although from the research this investigator has encountered it appears both systems are needed and that it is very difficult to separate them. 
BLOOM, L., Language Development: Form and Function in Emerging Grammars. Cambridge, Mass.: M.I.T. Press (1970).

BLOOM, L., Why not a pivot grammar. J. Speech Hearing Dis., 36, 40-50 (1971).

BOWERMAN, M., Early Syntactic Development: A Cross Linguistic Study with Special Reference to Finnish. Cambridge: Cambridge University Press (1973).

BOWERMAN, M., Discussion summary-Development of concepts underlying language. In R. L. Schiefelbusch and L. L. Lloyd (Eds.). Language Perspectives-Acquisition, Retardation, and Intervention. Baltimore: University Park Press (1974).

BROWN, R. W., The first sentences of a child and chimpanzee. In Psycholinguistics: Selected Readings, New York: The Free Press (1970).

BROWN, R. W., A First Language: The Early Stages. Cambridge, Mass.: Harvard University Press (1973).

CHAFE, W. L., Meaning and the Structure of Language. Chicago: University of Chicago Press (1970).

CLARK, E. V., Some aspects of the conceptual basis for a first language acquisition. In R. L. Schiefelbusch and L. L. Lloyd (Eds.), Language Perspectives-Acquisition, Retardation, and Intervention. Baltimore: University Park Press (1974).

DALE, P. S., Language Development: Structure and Function. New York: The Dryden Press (1972).

EDWARDS, D., Sensory-motor intelligence and semantic relations in early child grammar. Cognition, 2, 395-434 (1973).

FILLMORE, C., The case for case. In E. Bach and R. T. Harms (Eds.), Universals in Linguistic Theory. New York: Holt (1968).

FILLMORE, C. J., Types of lexical information. In D. D. Steinberg and L. A. Jakovits (Eds.), Semantics: An Interdisciplinary Reader in Philosophy, Linguistics and Psychology. Cambridge: Cambridge University Press (1971). 
FREEDMAN, P. P., and Carpenter, R. L., Semantic relations used by normal and language-impaired children at Stage I. J. Speech Hearing Res., 19, 784-795 (1976).

GREENFIELD, P. M., and Smith, J. H., The Structure of Communication in Early Language Development. New York: Academic Press (1976).

KUCZAJ, S. A., On the acquisition of a semantic system. J. Verbal Learning and Verbal Behavior, 14, 340-358 (1975).

LEE, L. L., Developmental Sentence Types: A method for comparing normal and deviant syntactic development. J. Speech Hearing Dis., $31,311-330$.

LEE, L. L., Developmental Sentence Analysis. Evanston: Northwestern University Press (1974).

McCAWLEY, J. D., The role of semantic in a grammar. In E. Bach and R. T. Harms (Eds.), Universals in Linguistic Theory. New York: Holt (1968).

McNEILL, D., Are there specifically linguistic universals? In D. D. Steinberg and L. A. Jakobovits (Eds.), Semantics: An Interdisciplinary Reader in Philosophy, Linguistics and Psychology. Cambridge: University Press (1971).

PIAGET, J., and Inhelder, B., The Psychology of the Child. New York: Basic Books (1969).

SCHLESINGER, I. M., Production of utterances and language acquisition. In D. I. Slobin (Ed.), The Ontogenesis of Grammar. New York: Academic Press (1971a).

SCHLESINGER, I. M., Learning grammar: From pivot to realization rule. In Huxley and Ingram (Eds.), Language Acquisition: Models and Methods. New York: Academic Press (1971b).

SCHLESINGER, I. M., Relational concepts underlying language. In R. L. Schiefelbusch and L. L. Lloyd (Eds.), Language PerspectivesAcquisition, Retardation, and Intervention. Baltimore: University Park Press (1974).

SINCLAIR DE-ZWART, H., Language acquisition and cognitive development. In T. E. Moore (Ed.), Cognitive Development and the Acquisition of Language. New York: Academic Press (1973).

SLOBIN, D. I., Universals in grammatical development in children. In G. B. Flores d'Arcois and W. M. Levelt (Eds.), Advances in Psycholinguistic Research. Amsterdam: North Holland Publishing (1970). 
SLOBIN, D. I., Cognitive prerequisites for the development of grammar. In C. A. Ferguson and D. I. Slobin (Eds.), Studies of Child Language Development. New York: Holt, Rinehart and Winston (1973). 
APPENDIX A

OBSERVER'S NOTES

Date:

Previous Comments

Utterance

Interpretation

Situation

MLU and Questions 


\section{APPENDIX B}

\section{DEVELOPMENTAL SENTENCE TYPES (DST) CLASSIFICATION OF PRESENTENCES}

\begin{tabular}{|c|c|c|}
\hline \multirow{3}{*}{ 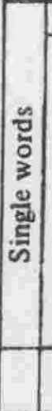 } & NOUN & DESIGNATOR \\
\hline & 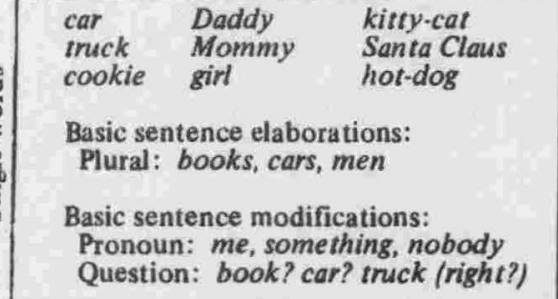 & $\begin{array}{l}\text { here, there } \\
\text { this, that } \\
\text { it } \\
\text { Basic sentence elaborations: } \\
\text { Plural: those, these } \\
\text { Basic sentence modifications: } \\
\text { Question: this? that? here? }\end{array}$ \\
\hline & NOUN ELABORATION & DESIGNATIVE ELABORATION \\
\hline 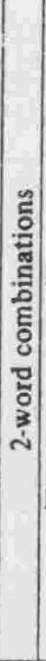 & $\begin{array}{l}\text { Noun phrase } \\
\text { Article: a car, the truck } \\
\text { Possessive: Doddy car, Billy truck } \\
\text { Quantifier: more car, other truck, two } \\
\text { boy } \\
\text { Adjective: big car, dirty truck, red } \\
\text { shoe } \\
\text { Attributive: baby bear, police car } \\
\text { Basic sentence elaborations: } \\
\text { Plural: the cars, more trucks } \\
\text { Additive: car truck, Mommy Daddy } \\
\text { Adverb: now car, truck too, car again } \\
\text { Subject-object: doggie bone, Daddy ball } \\
\text { Subject-locative: car garage, Mommy } \\
\text { window } \\
\text { Basic sentence modifications: } \\
\text { Pronoun: this one, my truck, her cookie } \\
\text { Negative: not car, not truck, not this } \\
\text { Question: a car? another truck (OK?) } \\
\text { Wh-question: what car? which one? } \\
\text { Conjunction: and car, and truck, and this }\end{array}$ & $\begin{array}{l}\text { Designator + noun } \\
\text { here car, there truck, this car, that } \\
\text { truck, it car, it truck } \\
\text { Basic sentence elaborations: } \\
\text { Plural: these cars, there trucks } \\
\text { Adverb: (that again = noun + adverb) } \\
\text { (there now, here again = fragments) } \\
\text { Basic sentence modifications: } \\
\text { Pronoun: here something, there one } \\
\text { Negative: (not this = noun + negative) } \\
\text { (not here, not there = fragments) } \\
\text { Question: that truck? this car (righr?) } \\
\text { Wh-question: what this? who that? } \\
\text { Conjunction: (and this = noun + conj.) } \\
\text { (and here, and there = fragments) }\end{array}$ \\
\hline & $\begin{array}{l}\text { Noun phrase } \\
\text { my big car, some more truck, a red box } \\
\text { Noun phrase + prepositional phrase } \\
\text { the car in front, the spot on the floor } \\
\text { Quantifier + prepositional phrase } \\
\text { all of them, some of the other cars } \\
\text { Basic sentence elaborations: } \\
\text { Plural: some other cars } \\
\text { Adverb: now the car, the other truck } \\
\text { too } \\
\text { Additive: the car the truck } \\
\text { Subject-object: the doggie another bone } \\
\text { Subject-locative: the car the garage } \\
\text { Basic sentence modifications: } \\
\text { Pronoun: his other truck, all of mine } \\
\text { Negative: not the car, not that one } \\
\text { Question: the other car? the boy too } \\
\text { (huh?) } \\
\text { Wh-question: what big car? which other } \\
\text { one? how much milk? how many } \\
\text { cookies? how about that one? what } \\
\text { about me? } \\
\text { Conjunction: and the car, car and truck }\end{array}$ & $\begin{array}{l}\text { Designator + noun phrase } \\
\text { here another car, thene a truck } \\
\text { this a red car, that my truck } \\
\text { it a big car, it my truck } \\
\text { Basic sentence elaborations: } \\
\text { Plural: here some cars, these big cars } \\
\text { Adverb: there car too, here car now } \\
\text { Additive: there Mommy Daddy } \\
\text { Basic sentence modifications: } \\
\text { Pronoun: that somebody car, here } \\
\text { his car } \\
\text { Negative: that not car, this not a } \\
\text { truck } \\
\text { Question: that a car? this a car (right?) } \\
\text { Wh-question: who that boy? what that } \\
\text { one? } \\
\text { Conjunction: here a car and truck }\end{array}$ \\
\hline
\end{tabular}


APPENDIX B-Continued

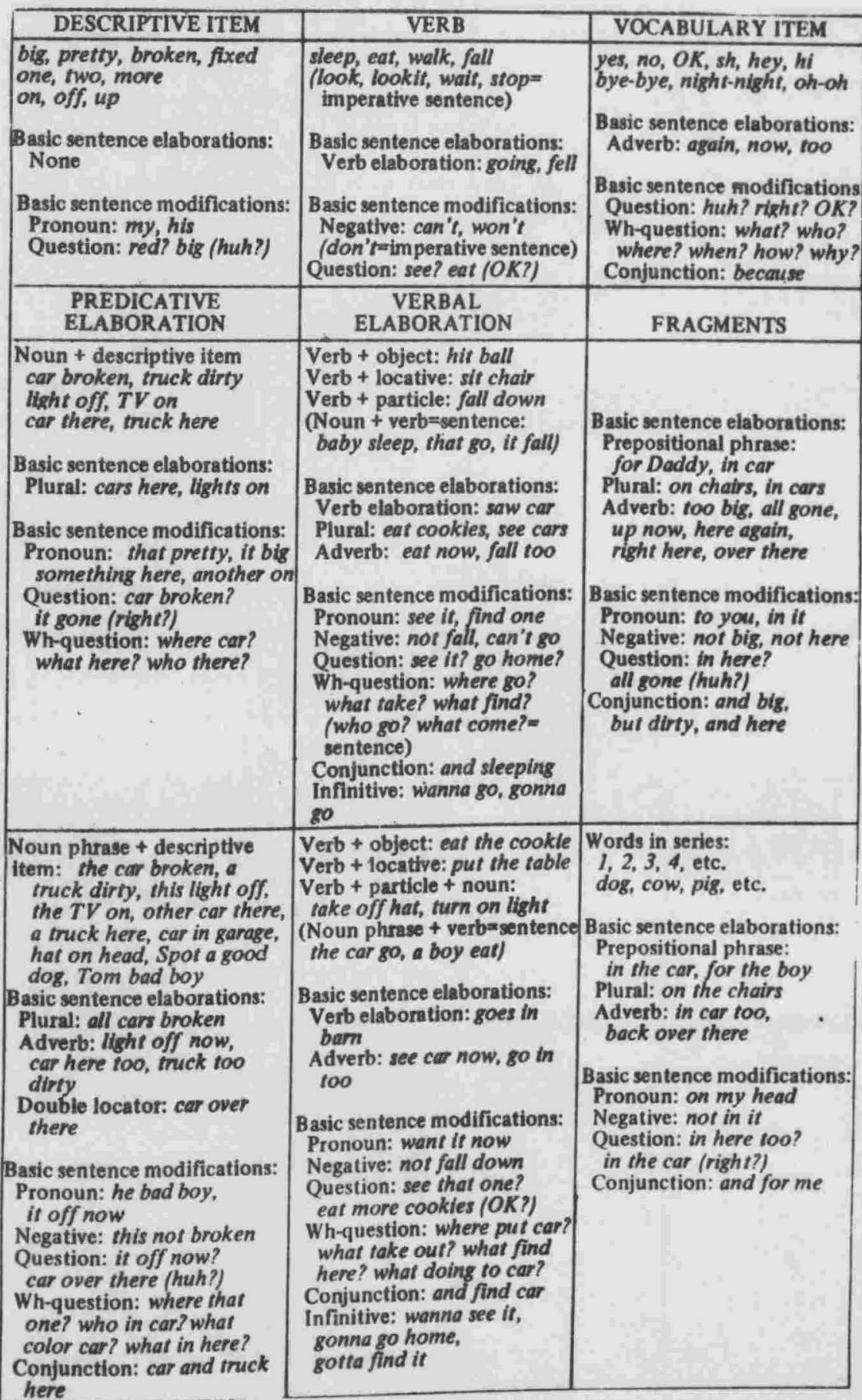


DEVELOPMENTAL SENTENCE SCORING (DSS)

\begin{tabular}{|c|c|c|c|c|}
\hline SCORE: & $\begin{array}{l}\text { INDEFINITE PRONOUNS } \\
\text { OR NOUN MODIFIFRS }\end{array}$ & $\begin{array}{l}\text { PERSONAL } \\
\text { PRONOUNS }\end{array}$ & MAIN VERBS & SECONDARY VERBS \\
\hline 1 & it, this, that & $\begin{array}{l}\text { Ist and 2nd person: I, } \\
\text { me, my, mine, you, } \\
\text { your(s) }\end{array}$ & 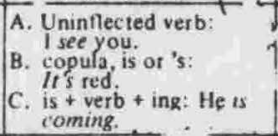 & \\
\hline 2 & & \begin{tabular}{|l|}
$\begin{array}{l}\text { 3rd person: he, him, his, } \\
\text { she, her, hers }\end{array}$ \\
\end{tabular} & $\begin{array}{l}\text { A. Frand ed: plays, } \\
\text { proved } \\
\text { Bregular past: } \\
\text { are, sew } \\
\text { c. Copula: am, are, } \\
\text { wost, were } \\
\text { D. Auxiliary am, are, } \\
\text { was, were.-" }\end{array}$ & 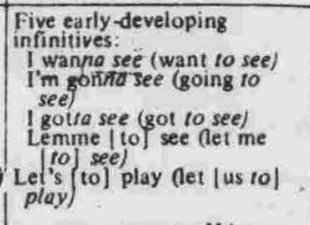 \\
\hline 3 & $\begin{array}{l}\text { A. no, some, more, all, } \\
\text { lot(s), one(s) two } \\
\text { (etc), other(s), } \\
\text { another } \\
\text { B. something, somer } \\
\text { body, someone. }\end{array}$ & $\begin{array}{l}\text { A. Plurals: we, us, our(s), } \\
\text { they, them, their } \\
\text { B. these, those }\end{array}$ & & $\begin{array}{l}\text { Non-complementing } \\
\text { infinitives } \\
\text { Istopped to play. } \\
\text { I'm afraid to look. } \\
\text { it's hard to do that. }\end{array}$ \\
\hline 4 & $\begin{array}{l}\text { nothing, nobody, none, } \\
\text { no one }\end{array}$ & & $\begin{array}{l}\text { A. can, will, may + verb: } \\
\text { may go } \\
\text { B. Obligat iny do + verb: } \\
\text { don go } \\
\text { C. Emphatic dn + varh: } \\
\text { I do see. }\end{array}$ & $\begin{array}{l}\text { Participle, present or past: } \\
\text { I see a boy munning. } \\
\text { I found the toy broken. }\end{array}$ \\
\hline 5 & & $\begin{array}{l}\text { Reflexives: myself, your- } \\
\text { self, himself, herself, } \\
\text { itself, themselves }\end{array}$ & & 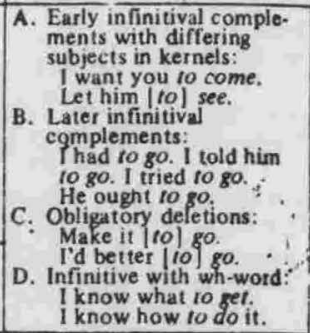 \\
\hline 6 & & $\begin{array}{l}\text { A. Wh-pronouns: who, } \\
\text { which, whose, whom, } \\
\text { what, that, how many, } \\
\text { how much } \\
\text { I know who came. } \\
\text { That's what I said. } \\
\text { B. Wh-word t in'tirtive: } \\
\text { I know whot to do } \\
\text { I know who(m) to take }\end{array}$ & $\begin{array}{l}\text { A. could, would, should, } \\
\text { might + verb: } \\
\text { might come, could be } \\
\text { B. Obligatory does, did + } \\
\text { verb } \\
\text { C. Emphatic does, did + } \\
\text { verb }\end{array}$ & \\
\hline 7 & $\begin{array}{l}\text { A. any, any thing, any- } \\
\text { body, any one } \\
\text { B. every, everything, } \\
\text { every body, everyone } \\
\text { C. both, few, many, each, } \\
\text { several, most, least, } \\
\text { much, next, first, last, } \\
\text { second (etc.) }\end{array}$ & $\begin{array}{l}\text { (his) own, one, oneself, } \\
\text { whichever, whoever, } \\
\text { whatever, } \\
\text { Take whatever you like. }\end{array}$ & $\begin{array}{l}\text { A. Passive with get, any } \\
\text { tense } \\
\text { Passive with be, any } \\
\text { tense } \\
\text { B. must, shall + verb: } \\
\text { must come } \\
\text { C. have + verb + en: } \\
\text { I've earen } \\
\text { D. have got: l'ye golich }\end{array}$ & $\begin{array}{l}\text { Passive infinitival } \\
\text { complement: } \\
\text { With get: } \\
\text { I have to get dressed. } \\
\text { I don't want to get hun. } \\
\text { With be: } \\
\text { I want to be pulled. } \\
\text { It's going to be locked. } \\
\end{array}$ \\
\hline 8 & - & & $\begin{array}{l}\text { A. have been + verb }+ \\
\text { ing } \\
\text { had been + verb + ing } \\
\text { B. modal + have + verb } \\
\text { +enimay have earen } \\
\text { c. modal + be + verb + } \\
\text { ing } \\
\text { could be playing } \\
\text { D. Other auxillary } \\
\text { combinations } \\
\text { should have been } \\
\text { sleeping }\end{array}$ & $\begin{array}{l}\text { Gerund: } \\
\text { Swinging is fun. } \\
\text { llike fishing. } \\
\text { He started laughing. }\end{array}$ \\
\hline
\end{tabular}




\section{APPENDIX C-Continued}

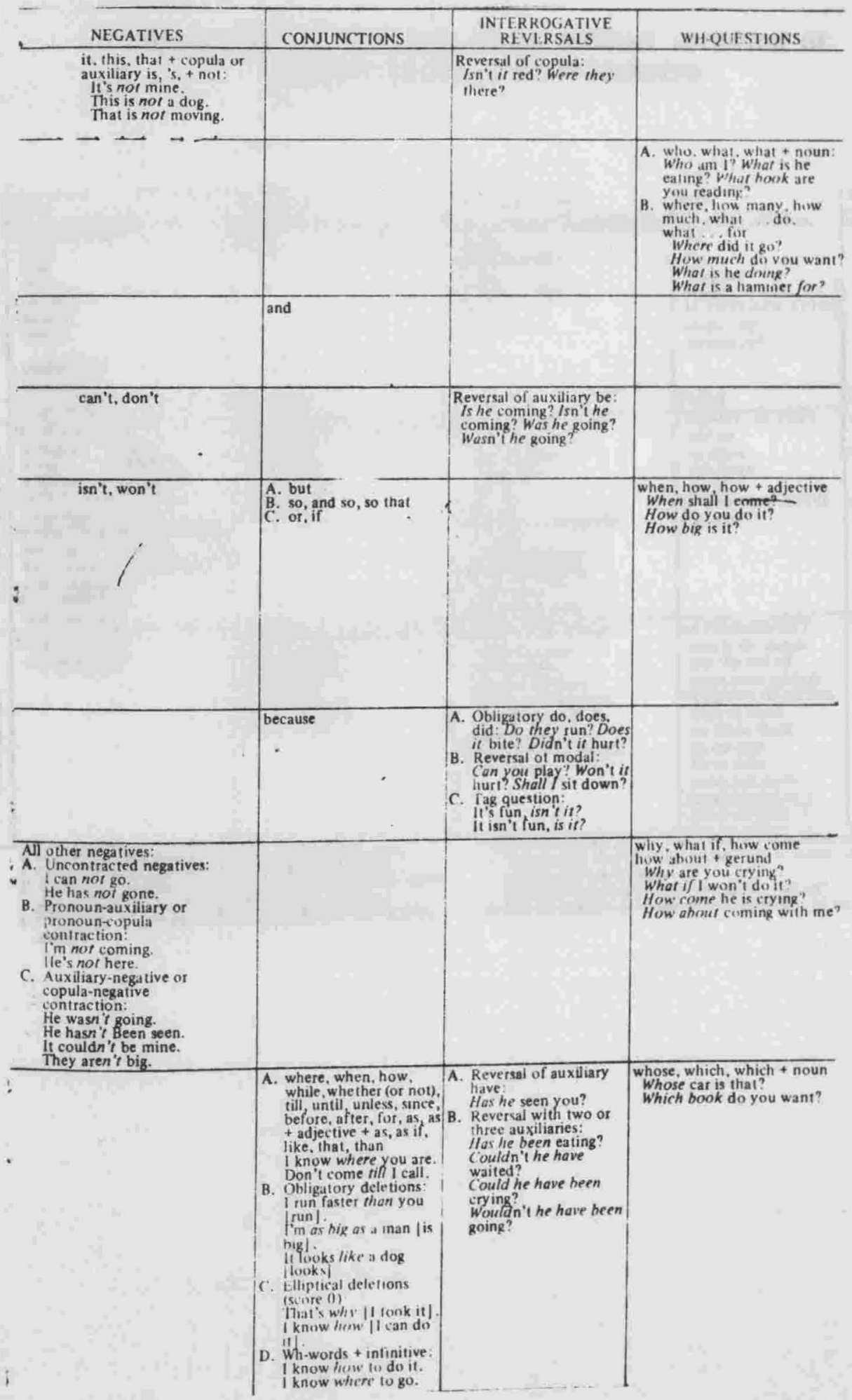




\section{APPENDIX D}

\section{DEVELOPMENTAL SENTENCE TYPES SHOWING LOCATION OF BROWN'S SEMANTIC RELATIONSHIPS}

\begin{tabular}{|c|c|c|c|c|c|}
\hline & Noun & Designator & Descriptive Item & |Verb & Vocabulary ttems \\
\hline 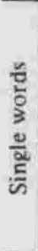 & $\begin{array}{l}\text { NOMINATION } \\
\text { baby } \\
\text { coat } \\
\text { chair } \\
\text { football } \\
\text { drawer } \\
\text { thumb } \\
\text { (ADDRESS) } \\
\text { Mommy }\end{array}$ & $\begin{array}{l}\text { (FNTITY)-LOCATIVE } \\
\text { there }\end{array}$ & $\begin{array}{l}\text { POSSESSOR (POSSESSION) } \\
\text { mine } \\
\text { RFCURRENCF } \\
\text { SOme } \\
\text { NONEXISTFNCF } \\
\text { away }\end{array}$ & $\begin{array}{l}\text { (AGENTI ACTIOA } \\
\text { fit } \\
\text { cui } \\
\text { seeping } \\
\text { eating } \\
\text { Artinsil A ATIVE } \\
\text { (usk. up } \\
\text { (jump) out }\end{array}$ & $\begin{array}{l}\text { INTIRITCTION } \\
\text { h. } \\
\text { nh } \\
\text { yeah } \\
\text { no } \\
\text { hey } \\
\text { what" } \\
\text { huh" }\end{array}$ \\
\hline & Noun Phrase & Designative & Predicative & Verbal & Fragments \\
\hline & \begin{tabular}{|l|} 
NOMINATION \\
a doggie a bike \\
a dog a a knife \\
a lambie a bookie? \\
ENTITY-LOCATIVE \\
chair baby 1 \\
POSSESSOR (POSSESSION) \\
my coat a mine \\
her thumb coat Mommy 2 \\
mine wagon \\
RECURRENC. \\
more picture \\
\end{tabular} & $\begin{array}{l}\text { DEMONSTRATIVI-FNTITY } \\
\text { there coat } \\
\text { this doggie } \\
\text { this knife } \\
\text { that Rossie } \\
\text { what that? }\end{array}$ & $\begin{array}{l}\text { FNTITY-LOCATIVI } \\
\text { something there } \\
\text { where spoon? } \\
\text { where baby? } \\
\text { hat on } \\
\text { hat off } \\
\text { FNTIIY-ATTRIBUTE } \\
\text { it stuck } \\
\text { baby night-night }{ }^{3} \\
\text { NONEXISTENCE } \\
\text { more away } 4 \\
\text { something away } 5 \\
\end{array}$ & $\begin{array}{l}\text { (AGENT) ACTION } \\
\text { put on } \\
\text { sit down } \\
\text { fall down } \\
\text { cut up } \\
\text { ACTION-LOCATIVE. } \\
\text { sit chair }\end{array}$ & $\begin{array}{l}\text { (ACTION) LOCATIVE } \\
\text { out water } \\
\text { (ENTITY) LOCATIVE } \\
\text { in bed } \\
\text { in there? } \\
\text { (MANNFR) } \\
\text { that way }\end{array}$ \\
\hline $\begin{array}{l}\text { है } \\
\text { हैं } \\
\text { हैं } \\
\text { हैं }\end{array}$ & $\begin{array}{l}\text { NOMINATION } \\
\text { the little bear }\end{array}$ & $\begin{array}{l}\text { DF MONSTRATIVE-ENTITY } \\
\text { that a button } \\
\text { that a drawer } \\
\text { that a girl } \\
\text { RirURRF.NCE } \\
\text { that a more } 6\end{array}$ & $\begin{array}{l}\text { ENTITY-LOCATIVE } \\
\text { button in there } \\
\text { bike in there } \\
\text { a lambie in there } \\
\text { Rossie on telephone } \\
\text { something in there } \\
\text { baby hat on } \\
\text { ENTITY-ATTRIBUTE } \\
\text { the TV on }\end{array}$ & $\begin{array}{l}\text { ACTION-OBJECT } \\
\text { watch the doggie } \\
\text { put the hat on } \\
\text { want more picture } \\
\text { ACTION-LOCATIVE } \\
\text { walk in there } \\
\text { sit down there } \\
\text { sit on that } \\
\text { fit in there } \\
\text { jump out water } \\
\text { NONEXISTENCE } \\
\text { drink all gone } 7\end{array}$ & $\begin{array}{l}\text { NONEXISTFNCE } \\
\text { all gone no }\end{array}$ \\
\hline & $\begin{array}{l}\text { 1. Accompanying action: the } \\
\text { 2. Clinician's expansion: Is tha } \\
\text { 3. Nighr-night has been consid } \\
\text { than a verb because it expan } \\
\text { 4. Clinician's expansion Arey } \\
\text { away? }\end{array}$ & 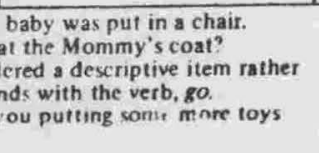 & \multicolumn{3}{|c|}{$\begin{array}{l}\text { 5. Accompanying action: they were putting away toys. } \\
\text { 6. That a more has been considered a } \\
\text { substituted for another } \\
\text { 7. Clinician's expansion Did the drint all up } \\
\text { 8. The no seemed to be added for cmphasiv at as a doubic negative. }\end{array}$} \\
\hline
\end{tabular}

